\title{
Digital Agency: Empowering Equity in and through Education
}

\author{
Don Passey $^{1}$ (D) Miri Shonfeld ${ }^{2} \cdot$ Lon Appleby $^{3} \cdot$ Miriam Judge $^{4} \cdot$ Toshinori Saito $^{5}$. \\ Anneke Smits ${ }^{6}$
}

Published online: 10 August 2018

(c) The Author(s) 2018

\begin{abstract}
This theoretical paper is concerned with conceptualising a major issue that faces all those concerned with and charged with influencing the future of equity in education-the need for digital agency (DA). The paper offers a rationale for this concern, highlights the importance of the concept and its practices, presents the challenges it brings, some current ways in which practices are tackling these challenges, and considers the theoretical foundation for how it might be addressed further in the future. The paper defines DA, and its three component parts-digital competence, digital confidence, and digital accountability. The paper argues that DA is a fundamental requirement for and through education, that it affects all citizens in a global society, and should be enabled through their ongoing and developing digital practices. The paper concludes with recommendations for different educational groups-including policy makers, practitioners, developers, and researchers.
\end{abstract}

Keywords Digital agency $\cdot$ Digital competence $\cdot$ Digital confidence $\cdot$ Digital accountability $\cdot$ Developing digital agency $\cdot$ Digital agency and education · Digital agency and equity

\section{Introduction: The Issue}

This paper is concerned with conceptualising a major issue that faces all individuals concerned with and charged with influencing the future of education - the need to have digital agency in a world with increasingly pervasive technologies. The paper presents a rationale for this concern, challenges that such a need brings, and considers through a theoretical

Don Passey

d.passey@lancaster.ac.uk

1 Department of Educational Research, Lancaster University, Lancaster LA1 4YD, UK

2 Kibbutzim College of Education, Namir Road 149, Tel Aviv-Yafo, Israel

3 Durham College, 2000 Simcoe Street North, Oshawa, ON, Canada

4 Dublin City University, Glasnevin, Whitehall, Dublin 9, Ireland

5 Seisa University, 5-14 Rokusencho, Ashibetsu, Hokkaido 075-0163, Japan

6 Windesheim University, Campus 2, 8017 CA Zwolle, The Netherlands 
foundation how these might be addressed. Technology has brought many benefits to the world, but coupled with this, there is increasing determinism arising from those technologies, experienced in all societies. As technologies are developed and managed by specific individuals, companies or corporations and then 'given to' and used by other individuals, this raises critical questions about how technology can or should be applied and used, and what roles education plays in that development. When we look at the world in 2018, the pictures that emerge can be mixed with regard to technologies; some would see powerful vested interests; others would see concerns about privacy and security; yet others would question how data can be handled appropriately, given innocently when completing access forms; while yet others would readily use software and resources that become accessible. While science and technology have brought us much innovation and invention, it is still true that progress rests on the power of freethinking. To guarantee such power to all citizens equitably, education on and with digital technologies should be designed and practiced to address challenges raised by these pictures, enabling citizens to take appropriate action, fundamentally based on notions and practices that we describe and develop in this paper-digital agency.

\section{A Definition of Digital Agency}

We will use the following definition throughout this paper: Digital Agency (DA)—consisting of digital competence, digital confidence and digital accountability-is the individual's ability to control and adapt to a digital world.

In this respect, DA enshrines the principles of access and equity as surely as Article 1 of the United Nations Declaration of Human Rights (1948), ensuring that as we go forward as a global society, driven by digital and other technologies yet to be invented, the individual will always retain her and his ability to control and adapt to accelerating changes in society through the exercise of digital competence, digital confidence, and digital accountability.

In this paper we refer to a number of related terms - digital skills, digital literacy, digital competence, digital confidence, and digital responsibility, digital autonomy, and digital accountability. A possible relationship of these more conceptual or category-concerned terms, drawn from definitions and features discussed in Sects. 3-6 following, is illustrated in Fig. 1. However, there is increasing recognition of additional elements as well as complexity of such relationships, arising from the important need to monitor and regularly include contemporary and emerging practical concerns and needs. We will consider this latter position in subsequent sections, specifically in Sects. 7 and 8, where an alternative diagrammatic form of relationships will be presented.

\section{Why Digital Agency is So Important}

In an increasingly technological world, there is a need to constantly reconsider and address the question of technological determinism and interactions between new technologies and society. The age-old question of whether technology controls us (technological determinism) or whether we as individuals shape new technologies as we use and interact with them (social shaping of technology), is central to the notion of DA. Currently, given the pace at which technology is advancing, whether it be in science, medicine, business and even civic society through the development of e-Government systems, the individual can become not just 


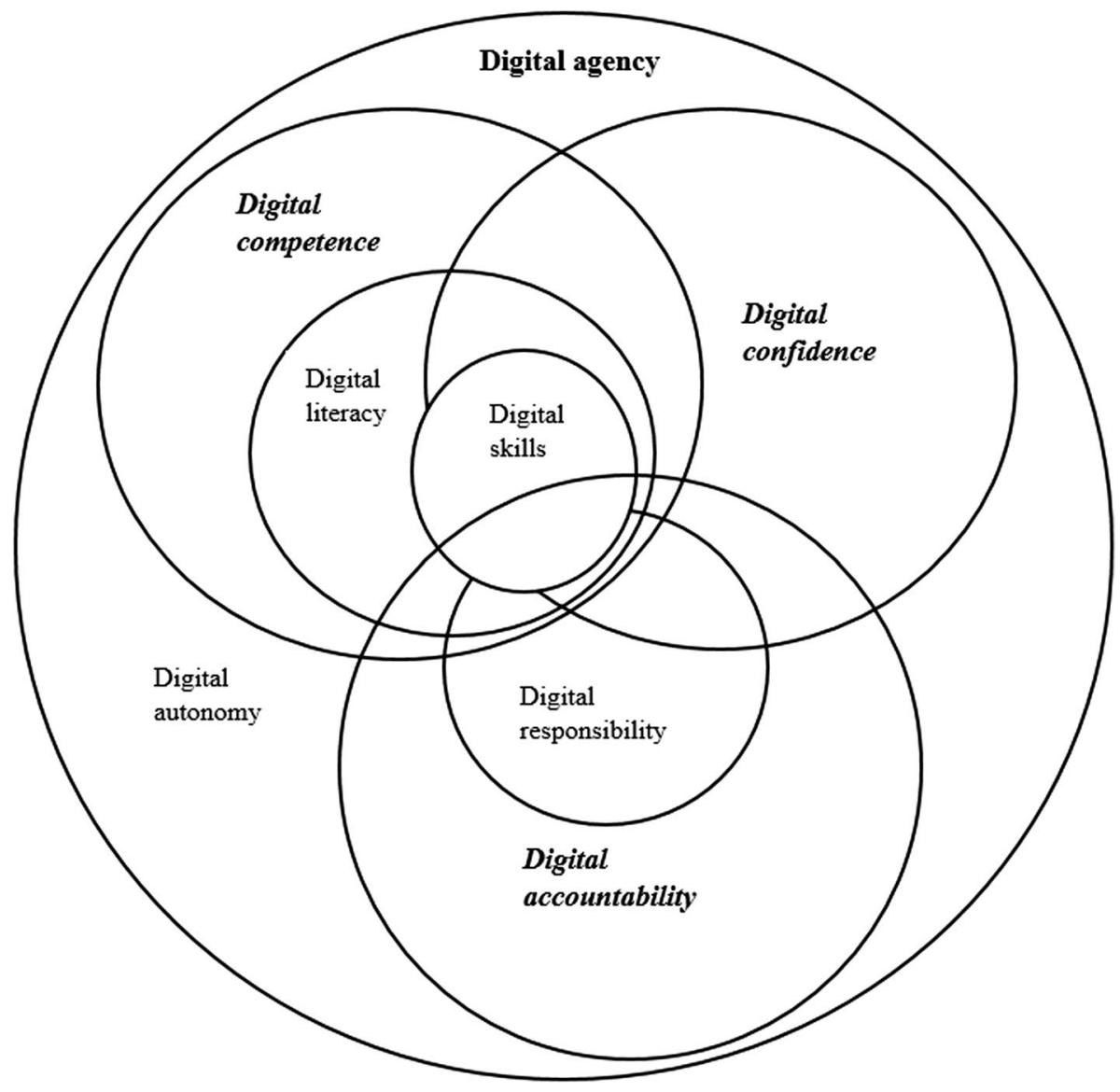

Fig. 1 Proposed relationships of terms related to digital agency

overpowered, but also disempowered. In the interests of social cohesion and individual wellbeing, policy makers need to ensure that policies are in place to equip citizens with the tools (cultural capital rather than hardware and access alone) that allow them to interact with confidence and competence with new technological tools and systems. At the same time, understanding implications for changes that new technologies embody, and impacts those have on how individuals behave, communicate and interact within a changing society, is a clear need for all citizens. In the absence of DA, there is a danger that individuals will feel less in control of their own lives and succumb to the belief that they have little or no say in how new technologies shape and control their lives. Therefore, DA as we have defined it is a way of empowering people to deal with new technologies so that they feel they have roles in how they adopt, adapt to and use them wisely and responsibly. 


\section{Digital Competence}

Digital competence is the ability to safely and effectively navigate the digital world (shown in Fig. 1 as embracing digital literacy and skills). First and foremost, digital competence has its foundations in traditional literacy and numeracy, knowledge and critical thinking. The Organisation for Economic Co-operation and Development (OECD) report, 'Students, computers and learning' (2015), shows the importance of traditional literacy and numeracy as a precursor to digital competence. The report states that at school, basic literacy and numeracy are more important for (future) digital equity than access to advanced technology and internet services. Traditional literacy and numeracy pave the way for knowledge acquisition. In rich learning environments where subject specific content is taught, rich mental networks can arise (Hirsch 2016). These mental networks enable (critical) thinking about specific content that is learned. Critical thinking is thus not a skill in its own right, but is fully dependent on content knowledge and practice (Willingham 2008). Based on foundations of literacy, numeracy, knowledge and critical thinking, digital literacy can arise, but only when explicitly taught and practiced. The dependency on the foundational skills (literacy, numeracy, knowledge and critical thinking) is easy to see, but digital literacy moves beyond these foundational skills. Illustrating this, Higgins et al. (2012) stated the following, "letting learners loose on the internet is a little like sending teenagers into the British Library and expecting them to make successful forays to support their learning" (p. 9). Our knowledge about fostering digital literacy is incomplete, and due to continuous change and expansion of the internet and associated technologies (blogs, wikis and videos), building this knowledge can be seen as 'shooting a moving target' (Leu et al. 2004). For our current conception of digital literacy, we follow the synthesis of the Dutch National Institute for Curriculum Development (SLO 2016). Their definition of digital literacy comprises four main components: (foundational) information and communication technology (ICT) skills, media literacy, information skills, and computational thinking (which, it can be argued, would include digital skills, but not exclusively). In terms of information skills and their relationship to the other components, a complex and progressively important aspect of dealing with digital information is the role of different world languages on the internet. More specifically, this concerns the hegemony of the English language and still untrustworthy translating machines. Equity on the internet, especially for adolescents and adults, seems more and more dependent on proficiency in English language (Macedo et al. 2015). Alongside English language proficiency, advancing stages of digital literacy not only incorporate critical use of internet resources, but also active production of resources on the internet such as video, blogs, websites and wikis. In this respect, currently, in terms of developing digital literacy, adolescents are reported to be more inclined to consumer roles than to producer roles, whereas digital equity is dependent on both (van den Beemt et al. 2011). Consequently, teaching and learning digital competence is a complex multi-stage process that can start from traditional foundational aspects of education, proceeding to more complex and productive aspects of digital literacy. 


\section{Digital Confidence}

According to the European Union (EU)'s Digital Agenda Scorecard (2015), 22\% of the European population has no digital skills (shown in Fig. 1 as embraced within digital confidence as well as digital competence). In eight countries, including a well-developed country like Italy, the figure is over $30 \%$, effectively meaning that over 18 million people in Italy alone are digitally illiterate. Furthermore, the scorecard indicates that one of the biggest barriers to internet access at home is a lack of skills, and perhaps more worryingly, this figure is increasing, rising from $33 \%$ in 2010 to $41 \%$ in 2014. Crucially, digital skills (a person's ability to use technology and associated software competently), is a core building block for digital confidence. This gaping digital skills and competence gap needs to be addressed in order to build digital confidence, especially among many digitally disenfranchised citizens, not just in Europe but also in developing countries, where figures are much lower (UNESCO 2017).

Given the importance of digital confidence as a core component of DA, it is important to avoid a superficial understanding of the term; this means dispelling the notion that digital confidence is merely a skills-based competency or perhaps even more alarmingly, an innate characteristic of 'millennials' or 'generation m' as commentators like Prensky (2001) would want us to believe. While young people may appear more adept with technology than older generations, and therefore more skilled or fluent in navigating devices and software, this outward display of confidence frequently masks inabilities to use technology effectively or judiciously. In his critique of the digital natives debate, Selwyn (2009) argues that empirical research portrays a more complex and nuanced picture of how young people actually use new technologies, rather than the digital native commentary promulgated by Prensky and other techno-centric commentators (Tapscott and Williams 2008; Veen and Vrakking 2006; Vandewater et al. 2007).

According to Selwyn, research on young people's technology use (as opposed to anecdotal observations) suggests that "young people's abilities to access digital technologies remain patterned strongly along lines of socio-economic status and social class, as well as gender, geography and the many other entrenched "social fault lines" (Golding 2000) which remain prominent in early twenty-first century society" (p. 372). This gap or "digital divide" in both inequality of access and engagement is further compounded by the rather limited scope of young people's actual use of technologies which more often than not are passive, consumerist and sporadic (Livingstone 2009; Crook and Harrison 2008). Recently, the Carnegie United Kingdom (UK) Trust Report (Wilson and Grant 2017) made the bold claim that "Young people are not digital natives" (p. 6) and that as many as 300,000 young people in the UK lack basic digital skills. In a similar vein, the UK's digital commissioner for children in her recent report (2018) has called for compulsory digital literacy and online resilience lessons for pupils aged 10-12 years, to help them cope with the emotional side of social media use rather than the current concentration on messages about online safety. All of these critiques suggest a lack of confidence in many young people's interactions and engagement with digital technologies.

Questions can be posed about levels of digital confidence among adults. Although most adults use technology regularly in work, even if their levels of home or leisure usage are more restricted, results from a series of studies carried out by the European Computer Driving Licence (ECDL) national operators in Switzerland, Germany, Austria, Finland and Denmark, show that adults display high levels of over-confidence in their digital abilities, frequently rating them highly, compared to reality. In Austria, 
while $94 \%$ of survey participants rated their skills as 'average' or 'good', only $39 \%$ achieved a corresponding test score when formally assessed. Of equal concern is the fact that gaps were found in users' skills levels when using basic programs such as word processing, spreadsheets and everyday online tools. There is strong evidence that continued lack of digital confidence is a key barrier to teachers' engagement with ICT in schools (Pelgrum 2001; Berner 2003; Judge 2013; McLeod and Carabott 2016), which given the pace of technological change and the current focus on curriculum reform to better prepare students for science, technology, engineering and mathematics (STEM) and 'hi-tech' jobs, is concerning.

It is clear that digital confidence is complex and multifaceted. It is not just about having skills to use technology and software-it is also about having confidence to use skill and knowledge levels to navigate other digital domains in a 'transferable' manner, while doing so in an agentic way. We propose that digital confidence consists of three components: the ability to expertly use a variety of popular computer applications and software, particularly the internet, with ease; the confidence to handle ICT in different contexts, for learning, for interacting with family and friends and societal participation such as accessing government services or purchasing goods and services online; and the exercise of digital autonomy, knowing the informed basis of one's choices and actions.

\section{Digital Accountability}

Accountability has been explained as a positive quality in organisations, focusing on the assessment of the actual and active behaviour of public agents (shown in Fig. 1 as embracing digital responsibility). It is seen as an institutional relation or arrangement in which an actor can be held to account by a forum (Bovens 2010). The digital age has changed sources of data, and governments are losing exclusive control over accountability (Vanhommerig and Karré 2014). When social media is so popular, when citizens are producers of data and publishing on the web is at everyone's fingertips, accountability is required of everyone. In the digital age, children can live in cyberspace and virtual schooling, social life can be determined by a single click, so cyber wellness and parent, teacher and student accountability become educational issues.

Digital accountability includes: digital responsibility for oneself and for others regarding one's digital actions; knowledge of the digital world and its ethical issues; understanding concerns and ensuring security and privacy; and understanding the impact of our digital activities. Therefore, policy makers and education systems must include accountability as part of the curriculum preparing students for DA. Educational settings must be proactive regarding accountability, recording cyber incidents, reviewing and reporting to appropriate authorities, developing policy and the teaching of digital citizenship practices. Accountability to authorities includes reporting to parents, about cyber incidents involving their children, while schools should actively cooperate with other agencies to help ensure a consistent and effective local digital citizenship strategy to ensure accountability (Searson et al. 2015). In higher education, students have more autonomy in the materials they use during the learning process, leading to increased engagement and individual accountability (Adams Becker et al. 2017). Individual accountability is clearly an important issue when learning occurs in teams, including instances in work life (Marx and Squintani 2009). 


\section{Digital Agency}

We consider digital agency to encompass elements of digital competence, digital confidence and digital accountability. DA can be considered as a notion or set of practices that relate to and arise from concepts of learner agency. Martin (2004) defined learner agency (rather than DA) as "the capability of individual human beings to make choices and act on these choices in a way that makes a difference in their lives" (p. 135). In a digital context, this implies that DA is concerned with choice, action, and making a difference to an individual's life. In a study on undergraduate students, Lindgren and McDaniel (2012) similarly highlighted the importance of digital technologies in enabling choice, action and making a difference to the work of the individual. Considering more the concept of levels of agency in learning activities, Schwartz and Okita (2009) differentiated factors that support high, rather than low, agency. They concluded that learning activities supporting high agency are: student centred; with student voice; taking a constructivist approach; are active; involve doing; are elected; engage through intent participation; and where learners are in control. Choice, action, and making a difference are again embodied within the features they identify, but, looking in depth at features concerned with choice, action, and making a difference, as Starkey (personal communication, May 30, 2017) states, DA is: "The ability for individuals to control and manage their use of digital technologies and online presence. This includes managing identity, initiating interactions, using technologies for self-identified purposes and modifying or developing digital tools" (p. 1). These requirements for developing DA are closely aligned with earlier conceptions of uses of digital technologies differentiated into 'consumer' or 'producer' activities and outcomes. The requirements and features that both Schwartz and Okita (2009) and Starkey (personal communication, May 30, 2017) identify are clearly associated strongly with 'producer' activities. However, there are important roles for 'consumer' activities, enabling the development of learner understanding and features such as purpose, modification and development of digital tools; 'consumer' forms of activities should certainly not be dismissed as being entirely unhelpful.

Some studies have explored how DA might be developed through learner agency. Bjørgen (2010) studied "examples of digital storytelling among 5th-7th graders in three Norwegian primary school classes" (p. 161). The author concluded that "digital storytelling might represent a boundary crossing enabling pupils to adopt new roles as producers of creative content, as mentors or guides, to explore new technology and software in a context different from that of outside school and to learn and develop competences related to production processes and multimodal resources" (p. 161). Erstad and Silseth (2008) also point to the importance of digital storytelling in this respect. With computing and computer science education currently being developed and integrated into curricula across increasing numbers of countries, the role of coding is important in developing producer activity also. As Corneliussen and Prøitz (2015) from their study in a rural code club in Norway state, "We find that coding through play activity is perceived as teaching more than simply the technical skills of programming. Although the fun aspect draws in children and volunteers, parents and instructors describe the code club as being about learning to understand and control the computer, and digital competence required for achieving success in society" (p. 95). However, they also argued that "the code clubs need an explicit recruitment strategy targeting girls in order to become an arena where girls can develop interest and competence in digital technologies" (p. 95). Important roles of intergenerational learning, and how these relate to learning and DA, are also touched on in this paper. And as de Almeida et al. 
(2015) state from their study of uses of the internet by children in Portugal, "Our study suggests that the erosion of generational territory markers is underway through children's intense and ubiquitous use of the Internet" (p. 1449).

Other studies have shown how DA has arisen from adult-focused projects managed within developing countries. Coelho et al. (2015) state from a project in South Brazil that "The main result was the possibility given to the population to choose to connect and use ICT for their own benefit... [but] Secondary results depend on individual choices" (p. 9). Similarly, Vaughan (2012) reports impacts of a project in Sri Lanka, aiming to develop societal improvement post-conflict, utilising the potentiality of digital technologies through government telecentres, a temple-based community ICT centre, and an e-village.

Some studies are pointing to the fact that digital activities are offering the potential for more intercultural social interaction; computing and coding activities are offering this potential also. For example, Dezuanni and Monroy-Hernandez (2012) state that "The Scratch Online Community enables young people to share their creative digital projects internationally with a level of ease that was impossible only a few years ago" (p. 59). They concluded that "online community spaces like Scratch might draw on social interaction to enhance intercultural understandings and learning through dialogue and creative practice" (p. 59). However, in this context, Gudmundsdottir (2010) warns from her study of digital competencies of 7th graders in four schools in South Africa that "In order to increase digital equity and decrease the digital divide, a renewed policy focus is needed which puts greater emphasis on addressing the severe inequalities of the learners within their school environment as well as outside of school, taking their home situation into consideration to a greater extent" (p. 84). And Hatlevik and Christophersen (2013) in their study of over 4000 students in 24 upper secondary schools identified the crucial importance of "The conditions at home, i.e. language integration and cultural capital, together with mastery orientation and academic aspirations did predict digital competence, and explained a substantial share of the total variation in digital competence" (p. 240).

It is clear from studies above that important elements of agency concern culture and interculturality (including language, engagement in student-centeredness, or being in control). A number of projects worldwide have explored these issues in undertaking their practices: for example, The Technology, Education, and Cultural Diversity (TEC) Center in Israel; The Global Classroom in Canada; The Dissolving Boundaries Project in Ireland; Clusters of schools in New Zealand that aim to develop agency through the use of digital technologies, including Manaia Kalani; and a scaffolding approach first developed to support indigenous Australian learners.

\section{The Challenges}

Today, as can be seen from examples in the previous section, human agency of individuals is influenced by changes in a social environment affected by the continued spread of uses of digital technology (Pangrazio 2014). The social environment continues to be subject to what currently are seen as irreversible changes, due to the incorporation of the developing potential of digital technology. Examples are: new styles of governance by using e-government (Bertot et al. 2010); expanding economic spheres that are based on electronic payment (Maurer 2012); realisation of smart societies that are accompanied by the digital control of lifelines (Nam and Pardo 2011); and dissemination of technology enhanced learning calling for rethinking on what is learning (Bayne 2015). 
This social change intervenes in the life choices for individuals in different situational arenas-embedded in political, economic, societal, and cultural aspects. Amidst this change, individuals are required to demonstrate their agency in such situations, in terms of carrying out social participation, undertaking decision making as a member of society, engaging in production and consumption, exercising choice with regard to policy and social systems, sharing and reproducing values and beliefs and so forth, if they are to fulfil their rights and duties as democratic citizens (Coleman and Blumler 2009).

In this context, we argue that DA should be understood as a capacity for individuals to choose 'control' over and 'adapt' for such changes in a social environment accompanying the spread of digital technology. The term 'control' can have two meanings, in accordance with Isaiah Berlin's well-known distinction of 'negative liberty' and 'positive liberty' (Carter 2016). The control associated with passive liberty works so that the extent of liberty will not be unilaterally defined by the changes of a social environment with the exploitation of digital technology, whilst the control associated with active liberty works so that individuals can gain the liberty of choosing realisation of a life worth living in times of such social changes. On the other hand, the term 'adapt' has an implication that individuals can adapt to upcoming social environments relying upon digital technology, having enough control over those changes in the social environment.

DA consisting of control over and adapting for social change with the spread of digital technology provides the basis for individuals to enjoy citizenship through democratic choices in society. This implies that the challenge for a society to realise DA will be focused on how the society can distribute conditions for individuals to demonstrate their agency in a society that is built on digital technology, since equitable distribution of the liberty of exercising agency is an essential premise to constitute a democratic society (Dahl 2000). More specifically, equitable distribution of DA in a society is in the first place a moral demand to sustain and strengthen a democratic state of a society standing upon digital technology. At the same time, the distribution of DA will be a practical requirement to stabilise a democratic society through creating potential possibilities for innovation which can bring about social vitality utilising digital technology (cf. Pellicer-Sifres et al. 2017). We consider that both aspects, moral and practical, should be emphasised at the same time in policy planning, as innovation arising from uses of digital technology can be utilised for democratic demands only in a society where citizenship is supported by DA (e.g. Rodotä 2007).

We propose the need to grasp contemporary challenges (identified in Fig. 2), which are imposed on society today, to guarantee individuals' equitable enjoyment of DA, in each of the three categories: digital competence, digital confidence, and digital accountability. Digital competence requires skills and abilities to enjoy the potential of digital technology as producers as well as consumers. Not only does digital literacy figure here, but also traditional literacy (including a knowledge of languages and numeracy), and critical thinking. In this context, digital confidence might be regarded as the foundation of digital autonomy, for taking control of social changes arising from uses of digital technology (suggesting a rather different relationship from that shown in Fig. 1). It highlights the importance of non-cognitive factors relating to self-affirmative attitudes, such as feeling at ease with uses of applications and software, and being confident to handle ICT in different contexts-in the family, community, and society. Digital accountability through this lens consists of personal capacities, acting with digital responsibility, which is a responsibility to oneself and for others in terms of digital actions. Knowledge of the digital world and ethical issues are a part of digital accountability, as are 


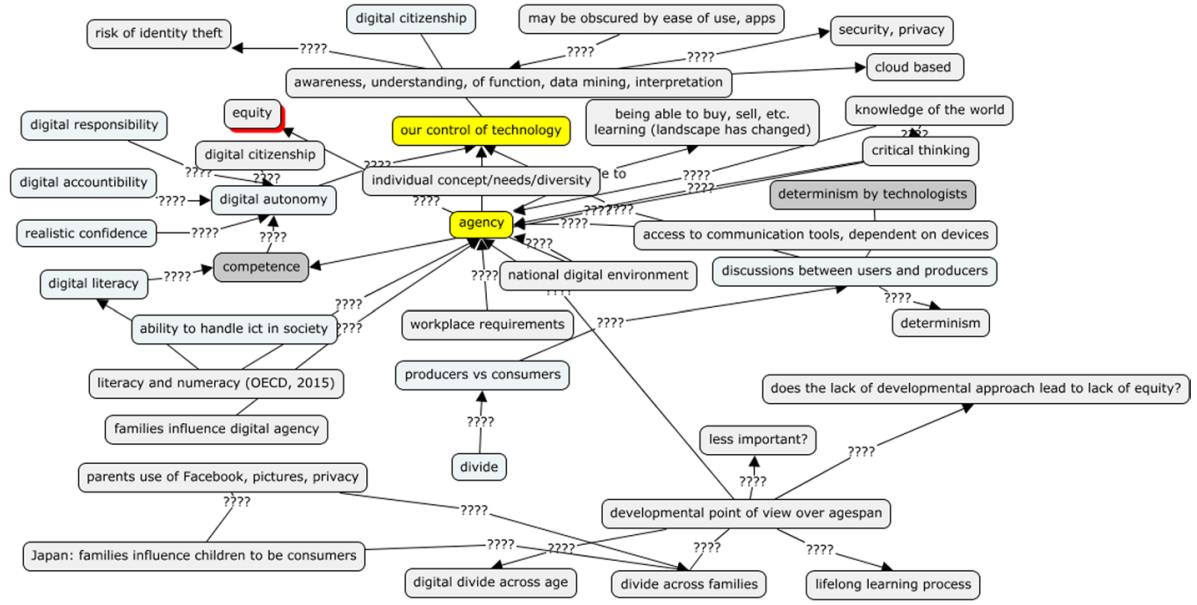

Fig. 2 Challenges arising from the concept of digital agency. (Note: whilst each of the items in this figure have been identified as factors affecting and involving DA, the relationship between them has not been fully explored or researched, so relationships are tentative and perceptual; question marks indicate degrees of uncertainty in this respect; arrows indicate suggested directions of influence, while lines may pass through other factors indicating a flow of influence)

understanding the impact of our digital activities and concerns with and ensuring security and privacy.

Since relationships among these three categories are in ways complementary (shown by the overlap of features in Fig. 1 and by the inter-related links in Fig. 2), we find elements that belong in every category when we consider a behaviour based on DA for people living with digital technology. Indeed, and on the contrary, when analysing a situation where DA is suppressed, it should be possible to specifically observe the suppression as a limitation arising from one or all factors belonging to any of the three categories. For instance, an individual may undertake some civil responsibility in the digital society with her/his own free will (for example, undertaking management of some public information system voluntarily, or construction of a website with high accessibility for disabled users). But, she/he can take on responsibility in the digital society only when acquiring a certain level of digital competence that allows the person to fulfil her/his responsibilities. However, in order to undertake the role with responsibility for others, merely having digital competence is not sufficient. That is, the person needs to acquire sufficient digital confidence to demonstrate digital competence for others. In addition, presenting one's own digital competence with responsibility for others is a choice of behaviour that cannot be established without the sense of digital accountability.

From the viewpoint of empowering equity in education, society needs to provide opportunities for all individuals, regardless of background, origin and attributes, to acquire understanding and practice of all elements belonging to the three categories which constitute DA. We argue that this is the most essential challenge for realising a society composed of citizens who own DA. What is important for societies is to provide such learning opportunities, not to instantly regard citizens as consumers of convenience that digital technology brings about, but rather regard them as producers and creators of value utilising digital technology. This shifting of view of learners from consumers to producers and creators corresponds to discussions on global educational reform promoted since the 1990s, such as 
key competencies and 21st century skills. Following such discussions, learning digital literacy, security, privacy, and computational thinking, for instance, merely as acceptance of existing decontextualised knowledge, is insufficient for learners to acquire and understand how to exercise DA in real contexts. Rather, there is a need to understand the perspective of collaborating with others as responsible members in various contexts of social reality, creating new values in such contexts, and sustaining society by created values. And this should be understood as an obligation for every society today, to continue to challenge in creating such places of learning, regardless of educational stage.

\section{Addressing the Challenges}

While there is no single challenge, there are similarly no simple answers as to how to address the challenges. Appropriate mobilisation of different sectors of society, as has already been implemented in e-city localities in some countries, is needed to explore ways to do this. Society as a whole must be involved, with determination to achieve outcomes across periods of time supported by regular monitoring and re-focus, which cannot easily be gained from a simple implementation. A building of understanding and awareness, a movement towards users informing the practices of developers, and a greater focus on producer activities (producing outcomes from programming, computing and digital creativity) rather than consumer activities (using resources and materials that others provide) must be in place.

Suggestions to address the challenges of DA will inevitably be based on today's technologies, which evolve quickly. What we can say with certainty is that as we go forward, we must be ready to extend our creativity at every new turn to ensure we do not lose sight of the opportunity that always lies beneath difficulty. Technologies that have knitted human societies together provide us with unique opportunities to get to know one another and deepen our mutual understanding. We have the opportunity to use the technologies we have invented to foster greater respect for one another. The power of the tools available to us is increasing, as their relative cost is decreasing. In parts of the world that have historically been among the less developed, investment in new communication and information technologies are presently most concentrated-Africa, India, China, the Far East. These tools can give individual users abilities to communicate and access information in a worldwide forum. They are engines of DA, and together with the emergence of the internet as an everyday presence in our lives, have the potential to empower the disadvantaged and open the minds of many others.

It is likely to be teachers and educators who may have the greatest role to play in ensuring that the tools can be most effectively employed as agents of constructive change. The teacher is a role model; a basic level of technical proficiency is no longer enough; DA training for teachers now needs to be rigorous. At the same time, we must re-visit the purpose of the classroom and re-imagine what it might be. How the learning can happen is an ongoing challenge when communication and information devices are readily available, allowing us to learn on our own so quickly. "The classroom itself is becoming a much more fluid and flexible concept. We should expect that the classroom of the future will increasingly focus on application and problem-solving with materials rapidly being updated and easily accessible through technology" (Rhonda Lenton, President, York University, Canada).

An example of a new classroom model that is proving successful with students and teachers is Canada's 'Global Classroom', based at Durham College, outside Toronto, 
Canada. 'Global classes' are hosted by professors from all faculties-they are interactive, high-definition, and livestreamed. Video conferencing is embedded into the curriculum; resources are posted on the class website in advance of the class; in a live face-to-face class, a brief presentation is given and people from diverse parts of the world explore the topic, guided by the host and often guests; livestream viewers are free to participate. After the class, collaborative assignments can be posted in a medium of choice. These global classes allow for an open exploration of shared interests and concerns, free of outside influence and geographic boundaries. Participants interact with provocative thinkers and doers, meet people from diverse backgrounds, exchange resources, and share culminating reflections.

\section{Recommendations}

We have argued that the concept and practices of DA require a systemic approach to implementation and enactment. In order to move towards a more systemic approach to enactment, our recommendations are as follows:

- Policy makers, educators and technology leaders must adopt and promote DA as a critical goal for social, civic and economic wellbeing. The compulsory education system is where most individuals will develop digital lifeskills to function as citizens in the digital society and employees in the digital economy. Informed by think-tank bodies such as UNESCO, the EU, the African Union and World Bank, national policy makers should develop DA curricula which reflect international research on current and future technology trends, respect local contexts and cultural sensitivities, and provide the competencies and attributes required for DA. Such curricula should foster intercultural communication and learning, engage students in the production of digital artefacts, and support collaborative learning and critical thinking.

- In any education system, policymakers and practitioners must recognise that the development of DA is largely dependent on the digital competencies and dispositions of teachers. Thus, there is an urgent need to address initial teacher training and ongoing teacher professional development in order to ensure that young people benefit from digitally relevant pedagogies that will shape their working lives, their sense of self-worth as well as their ethical, moral and civic sensibilities as they mature.

- DA must be guaranteed equitably for all citizens everywhere. This means paying particular attention to the DA needs of the digitally disenfranchised, such as marginalised and vulnerable people who have had limited or no experience of formal education. Government bodies, NGOs, community groups and technology leaders must work together to enable digital equity and inclusion for all, to ensure patterns of inequality and disadvantage in the offline world are not continually repeated in the online world with each successive digital development wave. This will require sustained investment in the non-formal education sector, further promoting intergenerational learning as well as the adoption of a more coherent approach to addressing the digital needs of the disenfranchised and disadvantaged.

- Policy makers, educators and employers need to support and promote the concept of DA as a lifelong learning skill, evolving along a continuum. Because of the innovative and ever-changing nature of technology, individuals will need to continually reskill and acquire new digital competencies throughout their lifetimes. In this respect, employers, 
education providers and accreditation bodies will have important roles to play in facilitating this, particularly in the adult population. The development of an international digital passport accredidation system for all citizens could be considered as a way of promoting DA as a lifelong learning concept.

- Finally, there is an important role of research in advancing our understanding of DA development. As technology develops, undoubtedly the concept of DA will need to be expanded and revised. Through conducting research in schools, homes, communities and workplaces, current researchers can support policy makers making informed decisions and choices about how to best promote and develop DA in society, how to address scaling-up challenges, and how tensions between needs of the private and public sectors and the overall civic good can be resolved. Such research can help to establish valuable baseline data about what policies and interventions work, under what conditions and when, as well as their effectiveness or otherwise. Corrective and new interventions can be identified and implemented. Perhaps more importantly, baseline data can be used by tomorrow's researchers to build more sophisticated and refined models of DA development, to address new societal challenges that will inevitably emerge.

\section{Conclusions}

As a result of increasing digitalisation of society, particularly since 2010, many aspects of society have been substantially organised and administered through digital systems, services and applications (UNESCO 2017). From education and healthcare to social welfare and legal systems, no sector has remained untouched, prompting both governments and international bodies to examine ways in which all citizens can become digitally literate. However, it is our contention that given the pervasive nature of digitalisation, the term 'digital literacy' does not adequately capture the sophisticated nature of today's, nor indeed tomorrow's, digital challenges. We argue that the term 'Digital Agency' offers a deeper, richer and more holistic concept and one which provides a blueprint for ensuring that people can engage with technology in a 'meaningful' and 'capital enhancing' way, as opposed to merely 'functioning with technology' (Pearce and Rice 2017). If people are to live fulfilled and enriched lives in a world where artificial intelligence and robotics will displace existing jobs (both blue and white collar), where data analytics will increasingly capture every online interaction for the benefit of large private and public organisations, individuals will need to have skills, disposition and mind-sets to confidently navigate such systems with confidence and autonomy; hence, the need for DA. Fundamentally, unless people have agency, they cannot act in their own interests, and are effectively powerless. Thus, equipping citizens with the skills and attributes required to exercise DA is a big societal challenge involving all stakeholders, including policy makers, technology leaders, practitioners and the research community.

Acknowledgements The research and involvement of Associate Professor Toshinori Saito was partially supported by JSPS KAKENHI Grant Number JP16K01136.

Open Access This article is distributed under the terms of the Creative Commons Attribution 4.0 International License (http://creativecommons.org/licenses/by/4.0/), which permits unrestricted use, distribution, and reproduction in any medium, provided you give appropriate credit to the original author(s) and the source, provide a link to the Creative Commons license, and indicate if changes were made. 


\section{References}

Adams Becker, S., Cummins, M., Davis, A., Freeman, A., Hall Giesinger, C., Ananthanarayanan, V., et al. (2017). NMC horizon report: 2017 library edition. Austin, TX: The New Media Consortium. https:// www.learntechlib.org/p/182005/. Accessed January 5, 2018.

Bayne, S. (2015). What's the matter with "technology-enhanced learning"? Learning, Media and Technology, 40(1), 5-20.

Berner, J. E. (2003). A study of factors that may influence faculty in selected schools of education in the commonwealth of virginia to adopt computers in the classroom. Abstract doctoral dissertation. George Mason University. ProQuest Digital Dissertations, UMI No. AAT 3090718.

Bertot, J. C., Jaeger, P. T., \& Grimes, J. M. (2010). Using ICTs to create a culture of transparency: E-government and social media as openness and anti-corruption tools for societies. Government Information Quarterly, 27(3), 264-271.

Bjørgen, A. M. (2010). Boundary crossing and learning identities-Digital storytelling in primary schools. International Journal of Media, Technology \& Lifelong Learning, 6(2), 161-178.

Bovens, M. (2010). Two concepts of accountability: Accountability as a virtue and as a mechanism. West European Politics, 33(5), 946-967.

Carter, I. (2016). Positive and negative liberty. In E.N. Zalta (Ed.). The stanford encyclopedia of philosophy. https://plato.stanford.edu/archives/fall2016/entries/liberty-positive-negative/. Accessed January $5,2018$.

Coelho, T. R., Segatto, A. P., \& Frega, J. R. (2015). Analysing ICT and development from the perspective of the capabilities approach: A study in South Brazil. The Electronic Journal of Information Systems in Developing Countries, 67(2), 1-14.

Coleman, S., \& Blumler, J. G. (2009). The Internet and democratic citizenship: Theory, practice and policy. Cambridge: Cambridge University Press.

Corneliussen, H. G., \& Prøitz, L. (2015). Kids Code in a rural village in Norway: Could code clubs be a new arena for increasing girls' digital interest and competence? Information, Communication \& Society, 19(1), 95-110.

Crook, C., \& Harrison, C. (2008). Web 2.0 technologies for learning at key stages 3 and 4. Coventry: Becta.

Dahl, R. A. (2000). On democracy. New Have, CT: Yale University Press.

de Almeida, A. N., Delicado, A., de Almeida Alves, N., \& Carvalho, T. (2015). Internet, children and space: Revisiting generational attributes and boundaries. New Media \& Society, 17(9), 1436-1453.

Dezuanni, M., \& Monroy-Hernandez, A. (2012). Prosuming across cultures: Youth creating and discussing digital media across borders. Revista Communicar, 38, 59-66. https://doi.org/10.3916/ C38-2011-02-06.

Erstad, O., \& Silseth, K. (2008). Agency in digital storytelling: Challenging the educational context. In K. Lundby (Ed.), Digital storytelling, mediatized stories: Self-presentations in new media (Vol. 52, pp. 213-232). New York, NY: Peter Lang.

EU Digital Scorecard. (2015). Human capital: Digital inclusion and skills. https://ec.europa.eu/digitalsingle-market/en/human-capital. Accessed January 5, 2018.

Golding, P. (2000). Forthcoming features: Information and communications technologies and the sociology of the future. Sociology, 34(1), 165-184.

Gudmundsdottir, G. (2010). From digital divide to digital equity: Learners' ICT competence in four primary schools in Cape Town, South Africa. International Journal of Education and Development Using ICT, 6(2), 84-105.

Hatlevik, O. E., \& Christophersen, K.-A. (2013). Digital competence at the beginning of upper secondary school: Identifying factors explaining digital inclusion. Computers \& Education, 63, 240-247.

Higgins, S., Xiao, Z., \& Katsipataki, M. (2012). The impact of digital technology on learning : A summary for the education endowment foundation. Durham: Durham University and The Education Endowment Foundation. https://v1.educationendowmentfoundation.org.uk/uploads/pdf/The_Impac t_of_Digital_Technologies_on_Learning_FULL_REPORT_(2012).pdf. Accessed January 5, 2018.

Hirsch, E. D. (2016). Why knowledge matters: Rescuing our children from failed educational theories. Cambridge, MA: Harvard Education Press.

Judge, M. (2013). Mapping out the terrain in school context: Identifying the challenges of ICT integration during an innovative project. Irish Educational Studies, 32(3), 309-333.

Leu, D. J., Kinzer, C. K., Coiro, J. L., \& Cammack, D. W. (2004). Toward a theory of new literacies emerging from the Internet and other information and communication technologies. Theoretical Models and Processes of Reading, 5(1), 1570-1613. 
Lindgren, R., \& McDaniel, R. (2012). Transforming online learning through narrative and student agency. Educational Technology \& Society, 15(4), 344-355.

Livingstone, S. (2009). Children and the Internet. Cambridge: Polity Press.

Macedo, D., Dendrinos, B., \& Gounari, P. (2015). Hegemony of English. Abingdon: Routledge.

Martin, J. (2004). Self-regulated learning, social cognitive theory, and agency. Educational Psychologist, 39, 135-145.

Marx, M. L., \& Squintani, F. (2009). Individual accountability in teams. Journal of Economic Behavior \& Organization, 72(1), 1-636.

Maurer, B. (2012). Mobile money: Communication, consumption and change in the payments space. Journal of Development Studies, 48(5), 589-604.

McLeod, A., \& Carabott, K. (2016). Students struggle with digital skills because their teachers lack confidence. The conversation, March 28, 2018. http://theconversation.com/students-struggle-with-digitalskills-because-their-teachers-lack-confidence-56071. Accessed January 5, 2018.

Nam, T., \& Pardo, T. A. (2011). Smart city as urban innovation: Focusing on management, policy, and context. In Proceedings of the 5th international conference on theory and practice of electronic governance-ICEGOV'11 (p. 185). http://doi.org/10.1145/2072069.2072100.

OECD. (2015). Students, computers and learning: Making the connection. Paris: OECD Publishing. https:// doi.org/10.1787/9789264239555-en.

Pangrazio, L. (2014). Reconceptualising critical digital literacy. Discourse: Studies in the cultural politics of education, 37(2), 163-174.

Pearce, K., \& Rice, R. (2017). Somewhat separate and unequal: Digital divides, social networking sites, and capital-enhancing activities. Social Media and Society, 3(2), 1-16.

Pelgrum, W. J. (2001). Obstacles to the integration of ICT in education: Results from a worldwide educational assessment. Computers \& Education, 37(2), 163-178.

Pellicer-Sifres, V., Belda-Miquel, S., López-Fogués, A., \& Boni Aristizábal, A. (2017). Grassroots social innovation for human development: An analysis of alternative food networks in the city of Valencia (Spain). Journal of Human Development and Capabilities, 18(2), 258-274.

Prensky, M. (2001). Digital natives, digital immigrants part 1. On the Horizon, 9(5), 1-6.

Rodotä, S. (2007). Democracy, innovation, and the information society. In P. Goujon, S. Lavelle, P. Duquenoy, K. Kimppa \& V. Laurent (Eds.), The Information Society: Innovation, legitimacy, ethics and democracy In honor of professor Jacques Berleur. Boston, MA: Springer.

Schwartz, D. L., \& Okita, S. (2009). The productive agency in learning by teaching. Stanford, CA: Stanford University School of Education.

Searson, M., Hancock, M., Soheil, N., \& Shepherd, G. (2015). Digital citizenship within global contexts. Education and Information Technologies, 20(4), 729-741.

Selwyn, N. (2009). The digital native-Myth and reality. Aslib Proceedings, 61(4), 364-379.

Stichting Leerplan Ontwikkeling. (2016). Leerlijnen Digitale Geletterdheid. Retrieved 2 January 2018 from: http://curriculumvandetoekomst.slo.nl/projecten/leerlijnen-digitale-geletterdheid.

Tapscott, D., \& Williams, A. (2008). Wikinomics: How mass collaboration changes everything. New York, NY: Atlantic.

UNESCO. (2017). Digital skills for life and work. Paris: UNESCO Publishing.

van den Beemt, A., Akkerman, S., \& Simons, P. R. J. (2011). Patterns of interactive media use among contemporary youth. Journal of Computer Assisted learning, 27, 103-118.

Vandewater, E., Rideout, V., Wartella, E., Huang, X., Lee, J., \& Shim, M. (2007). Digital childhood. Pediatrics, 119(5), 1006-1015.

Vanhommerig, I., \& Karré, P. M. (2014). Public accountability in the internet age: Changing roles for governments and citizens. International Review of Public Administration, 19(2), 206-217.

Vaughan, D. (2012). Sri Lanka: Using information and communications technology to build capabilities for well-being in post-conflict communities. In F. Panzironi \& K. Gelber (Eds.), The capability approach: Development Practice and Public Policy in the Asia-Pacific Region. Abingdon: Routledge.

Veen, W., \& Vrakking, B. (2006). Homo Zappiens: Growing up in a digital age. London: Continuum.

Willingham, D. T. (2008). Critical thinking: Why is it so hard to teach? Arts Education Policy Review, 109(4), 21-32.

Wilson, G., \& Grant, A. (2017). NotWithoutMe: A digital world for all. Carnegie UK Trust: Dunfermline. https://www.carnegieuktrust.org.uk/publications/digitalworld/. Accessed January 5, 2018. 